\title{
Politique
}

Politique

\section{André Donneur, L'Alliance fragile. Socialistes et communistes français (1922-1983), Montréal, Nouvelle Optique, 1984, 319 p.}

\section{George Ross}

Numéro 8, automne 1985

Innovations et politiques technologiques

URI : https://id.erudit.org/iderudit/040511ar

DOI : https://doi.org/10.7202/040511ar

Aller au sommaire du numéro

Éditeur(s)

Société québécoise de science politique

ISSN

0711-608X (imprimé)

1918-6584 (numérique)

Découvrir la revue

Citer ce compte rendu

Ross, G. (1985). Compte rendu de [André Donneur, L'Alliance fragile. Socialistes et communistes français (1922-1983), Montréal, Nouvelle Optique, 1984, 319 p.] Politique, (8), 177-179. https://doi.org/10.7202/040511ar d'utilisation que vous pouvez consulter en ligne.

https://apropos.erudit.org/fr/usagers/politique-dutilisation/ 
André Donneur, L'Alliance fragile. Socialistes et communistes français (1922-1983), Montréal, Nouvelle Optique, 1984, 319 p.

Dans L'Alliance fragile André Donneur a trouvé un sujet de choix, les alliances entre communistes et socialistes dans la vie politique française. Dans la plupart des démocraties industrialisées on trouve une gauche unifiée plus ou moins social-démocratisante. Tel n'est pas le cas pour la France, et c'est ça qui fait l'intérêt du livre de Donneur. Dès le $19^{e}$ siècle, le mouvement ouvrier français a été marqué par de profondes divisions. Suite au Congrès de Tours (1921) il s'est bel et bien installé dans un pluralisme quasi-permanent. Par conséquent la gauche française est devenue un système politique à part où chacune des forces présentes se sont senties obligées de revoir constamment la question d'alliance.

C'était Étienne Fajon, un vieux routier communiste, qui a su le mieux capter l'esprit de ce pluralisme dans le titre de son livre L'Union est un combat. Depuis la scission de 1921 le mouvement ouvrier a été impliqué dans un jeu politique hyper-compliqué. Au départ chaque grande famille - soit communiste, soit socialiste - avait intérêt à affaibilr l'autre pour assurer sa propre hégémonie, afin de pouvoir imposer ses projets à la société française. Cependant en même temps chaque famille avait besoin, pluralisme obligeait, de s'allier avec l'autre pour multiplier la force de la gauche en général et pour accéder au pouvoir. Jeu diabolique, donc. On avait besoin d'alliés pour arriver au bout de sa propre stratégie mais simultanément on avait besoin de réduire ces mêmes alliés pour faire prévaloir ses propres projets. Ici, pas besoin d'ajouter des facteurs plus ésotériques, comme la forme spécifique d'organisation des partis ou leurs attaches internationales pour comprendre l'essentiel. Quand primait le combat intra-gauche, la gauche française était historiquement incapable d'alliance, laissant le champ ouvert à une politique de droite. Quand les grandes forces de gauche ont pu surmonter une partie de leurs différends 
en s'alliant, le combat s'est simplement déplacé vers l'intérieur de l'alliance, qui tôt ou tard finissait par sombrer dans la division. Les rares moments d'alliances consommées ont été de grandes périodes de réforme et de renouvellement pour la société française. Mais ils ont tous été d'une très courte durée - 3-4 ans pour le Front Populaire et la période de la Résistance et Libération, un peu plus pour l'Union de la Gauche récemment. Voilà pourquoi même avec une gauche à vocation majoritaire, la France a été plus souvent gouvernée par la droite.

L'Alliance Fragile fait un excellent examen détaillé de chacun des quatre épisodes, le Front Unique avorté des années 1920, le Front Populaire, le Front National sorti de la Résistance et l'Union de la Gauche des années 1960-1970. Pour chaque épisode Donneur révèle des facteurs contextuels qui ont poussé communistes et socialistes à s'allier, leurs stratégies, les influences internationales en jeu, le côté "programmatique», les accomplissements et échecs de l'alliance ainsi que les causes précises de l'ultime et inévitable rupture. Chacun des grands chapitres se termine aussi avec une comparaison historico-analytique entre l'épisode décrit et ceux d'avant. Donneur a le grand mérite de ne pas céder aux analyses simplistes, souvent monocausales, de ces événements. En particulier il refuse de jouer le jeu anti-communiste courant dans la littérature française qui consiste à répéter le catéchisme «tout a été décidé à Moscou, " «... la faute au PCF totalitaire et machiavélique, » etc. Dans L'Alliance fragile nous trouvons des acteurs politiques, y compris le PCF, qui doivent répondre aux multiples défis qu'ils n'arrivent pas souvent à maîtriser, qu'ils soient internationaux, organisationels, électoraux, sociaux, même individuels.

Pour ce qui est des rapports entre alliés communistes et socialistes dans la vie politique moderne en France, on a ici un travail de synthèse quasi-définitif. On pourrait contester certains détails ici et là (par exemple, les circonstances de rupture en mai 1947) mais en général Donneur réussit admirablement à bien 
peser toutes les variables. Par exemple, il a le rare bon sens d'accréditer le poids de vrai différends "programmatiques» dans la rupture PCF-PS de 1977 que la plupart des spécialistes explique par les seuls calculs électoraux du PCF (ou pire, par la «main de Moscou.») Malheureusement, Donneur a terminé son livre un peu trop tôt pour faire une analyse approfondie du moment bizarre et très important d'alliance fragile qui a pris fin en juillet 1984.

On peut regretter que Donneur n'ait pas voulu explorer davantage les effets systémiques des «alliances fragiles» pour la vie politique française. Le fait même de la structuration pluraliste de la gauche française a eu une très grande influence sur les formes institutionnelles et idéologiques de toute la vie politique et sociale en France. Donneur a aussi tendance à négliger les effets cumulatifs de cet enchaînement répétitif d'alliances sur les partis de gauche eux-mêmes. On pourrait bien écrire une histoire de l'évolution du PCF à partir de ses expériences d'alliance - sa «nationalisation» réussie dans le Front Populaire et le Front National l'ont pourvu d'un stock de symboles et d'habitudes stratégiques qui l'ont plus tard emprisonné pendant l'Union de la Gauche et enfin l'ont mené à sa perte et au chaos stratégique et théorique qui le caractérise à présent. Les socialistes ont vécu une histoire analogue. Le fait d'avoir poursuivi contre vents et marées une stratégie d'Union, d'avoir voulu une alliance fragile dans la période contemporaine a profondément agi sur les structures, les idées et, finalement, le sort, du PS. Infléchi à gauche dans son programme et son idéologie par l'Union de la Gauche, le PS est venu au pouvoir en 1981 avec une plate-forme qu'il ne voulait pas et, qui plus est, qu'il ne comprenait pas vraiment. La suite, échec économique, échec politique, défaite probable, est bien connue. Enfin, on n'a pas le droit de critiquer un auteur pour le livre qu'il n'a pas écrit. Ici André Donneur nous présente un argument qui nous fait beaucoup réfléchir. Que demander de plus? 